\title{
Avaliação do potencial de germinação de sementes de duas espécies, exótica e nativa, de Fabaceae como estratégia de colonização em ambiente degradado
}

\author{
Evaluation of the seed germination potential of two species, exotic and native, of Fabaceae as a \\ colonization strategy in a degraded environment \\ Evaluación del potencial de germinación de semillas de dos especies, exótica y nativa, de Fabaceae \\ como estrategia de colonización en un entorno degradado
}

ORCID: https://orcid.org/0000-0002-4667-0726 Universidade do Estado da Bahia, Brasil

E-mail: leticialvesbio@gmail.com

Luis Carlos Soares Queires

ORCID: https://orcid.org/0000-0002-8601-2461 Universidade do Estado da Bahia, Brasil E-mail: lqueires@uneb.br

Maria Dolores Ribeiro Orge

ORCID: https://orcid.org/0000-0002-0018-9574 Universidade do Estado da Bahia, Brasil E-mail: mdrorge@uneb.br Enéas Lima Santos

ORCID: https://orcid.org/0000-0002-2608-173X Universidade do Estado da Bahia, Brasil
E-mail: eneas-santos@hotmail.com

Cláudio Roberto Meira de Oliveira

ORCID: https://orcid.org/0000-0002-3077-8353 Universidade do Estado da Bahia, Brasil E-mail: crmoliveira@uneb.br

Ludmilla de Santana Luz

ORCID: https://orcid.org/0000-0002-4844-0772 Universidade do Estado da Bahia, Brasil E-mail: milaaluz@hotmail.com

Wilma Santos Silva

ORCID: https://orcid.org/0000-0003-2786-7619 Universidade do Estado da Bahia, Brasil E-mail: wilmasantosbio11@outlook.com

\begin{abstract}
Resumo
O potencial de germinação de sementes de duas espécies de Fabaceae foi avaliado como estratégia de colonização de ambiente degradado. Sementes das espécies exótica Leucaena leucocephala (leucena) e nativa Enterolobium contortisiliquum (tamboril) foram tratadas por escarificação física (cocção a $\left.100^{\circ} \mathrm{C}, 10 \mathrm{~min}\right)$ e química $\left(\mathrm{H}_{2} \mathrm{SO}_{4}\right.$ conc., $15 \mathrm{~min}$ ), cultivadas em terra vegetal e vermiculita. Para ambas as espécies vegetais, a alta temperatura inviabilizou as sementes, mas a escarificação por ácido foi eficiente. Apesar de baixo, o potencial de germinação da espécie nativa, $30 \%$ e $40 \%$, foi o dobro da espécie exótica, $15 \%$ e $20 \%$, respectivamente em terra vegetal e vermiculita. O resultado do grupo controle mostrou que o tipo de substrato não influenciou o processo de germinação e apenas as sementes da espécie exótica germinaram nos dois substratos. Espécies exóticas são invasoras agressivas pela baixa exigência para germinação e consequente eficiência de colonização em áreas degradadas. Em condições naturais, a superação da dormência e a germinação de sementes podem ocorrer após tratamento ácido no estômago dos dispersores, como aves e mamíferos terrestres, e o contato com a umidade do solo. O potencial de germinação da espécie nativa $E$.
\end{abstract}


contortisiliquum, superior ao da exótica L. leucocephala, configura uma vantagem estratégica da espécie nativa (pioneira longeva/secundária inicial) de floresta semidecídua e confirma seu papel ecológico para recuperação de áreas degradadas do domínio Mata Atlântica no estado da Bahia (Brasil).

Palavras-chave: Sementes; Dormência; Escarificação; Germinação.

\begin{abstract}
The seed germination potential of two species of Fabaceae was evaluated as a degraded environment colonization strategy. Seeds of the exotic species Leucaena leucocephala (leucena) and the native Enterolobium contortisiliquum (tamboril) were treated by physical scarification (cooking at $100^{\circ} \mathrm{C}, 10 \mathrm{~min}$ ) and chemical $\left(\mathrm{H}_{2} \mathrm{SO}_{4}\right.$ conc., $\left.15 \mathrm{~min}\right)$, cultivated in soil and vermiculite. For both plant species, the high temperature made the seeds impossible, but acid scarification was efficient. Although low, the germination of the native species, $30 \%$ and $40 \%$, was twice the exotic one, $15 \%$ and $20 \%$, respectively in soil and vermiculite. The control group showed that the type of substrate did not influence the germination process, and here only seeds of the exotic species germinated in the two substrates. Exotic species are aggressively invasive by the low requirement for germination and consequent efficiency of colonization in degraded areas. Under natural conditions, the overcoming of dormancy and seed germination can occur after acid treatment in the stomach of dispersers, such as birds and terrestrial mammals, and the contact with soil moisture. The germination of the native species E. contortisiliquum, superior to the exotic L. leucocephala, configures a strategic advantage of the native species (long-term pioneer/early secondary) of semideciduous forest and confirms its ecological role for the recovery of degraded areas of the Atlantic Forest domain in the state of Bahia (Brazil).
\end{abstract}

Keywords: Seeds; Dormancy; Scarification; Germination.

\title{
Resumen
}

El potencial de germinación de las semillas de dos especies de Fabaceae fue evaluado como una estrategia de colonización de ambiente degradado. Semillas de las especies exótica Leucaena leucocephala (leucena) y nativa Enterolobium contortisiliquum (tamboril) fueron tratadas por escarificación física (cocción a $100^{\circ} \mathrm{C}, 10 \mathrm{~min}$ ) y química $\left(\mathrm{H}_{2} \mathrm{SO}_{4}\right.$ conc., $\left.15 \mathrm{~min}\right)$, cultivadas en tierra orgánica y vermiculita. Para ambas especies vegetales, la alta temperatura hizo inviables las semillas, pero la escarificación ácida fue eficiente. Aunque baja, el potencial de germinación de la especie nativa, $30 \%$ y 40\%, fue el doble de la especie exótica, $15 \%$ y 20\%, respectivamente en tierra orgânica y vermiculita. El resultado del grupo control mostró que el tipo de sustrato no influyó en el proceso de germinación y sólo las semillas de la especie exótica germinaron en ambos sustratos. Las especies exóticas son invasoras agresivas por el bajo requisito de germinación y la consiguiente eficiencia de colonización en áreas degradadas. En condiciones naturales, la superación de la latencia y la germinación de semillas puede ocurrir después del tratamiento ácido en el estómago de los dispersadores, como aves y mamíferos terrestres, y el contacto con la humedad del suelo. El potencial de germinación de la especie nativa E. contortisiliquum, superior al de la exótica L. leucocephala, configura una ventaja estratégica de la especie nativa (pionera de largo tiempo/secundaria inicial) de bosque semicaducifolio y confirma su papel ecológico para la recuperación de áreas degradadas del dominio del Bosque Atlántico en el estado de Bahía (Brasil).

Palavras chave: Semillas; Dormición; Escarificación; Germinación.

\section{Introdução}

Na simplicidade da estrutura da semente está sua fisiologia extraordinária e a capacidade de sobreviver a longos períodos com conteúdo de água de até 10\% (Metivier, 1979). A redução do metabolismo pode dar-se em resposta ao estresse hídrico, térmico ou oxidativo. As sementes podem passar um longo período de dormência mesmo em condições ambientais propícias de luminosidade, temperatura, umidade e pH. Esta capacidade aumenta a probabilidade de sobrevivência da espécie e sua conservação até que a semente quiescente germine sob condições favoráveis (Cardoso, 2009).

Entre as sementes, o tegumento do tipo rígido é o mais comum e a impermeabilidade é sua principal característica. A dormência tegumentar depende fortemente de fatores externos para ser superada e possibilitar assim o processo de germinação (Metivier, 1979). Em função da constituição genética da espécie, a dormência é instalada na fase de maturação da semente ainda na planta-matriz, através de mecanismos básicos de sinalização e bloqueio no embrião. A dormência pode dar-se por imaturidade do embrião (dormência morfológica) ou impermeabilidade do próprio tegumento da semente (dormência física) (Cardoso, 2009). A ruptura desse tegumento possibilita a entrada de gases e água, maior sensibilidade à luz e à temperatura, promovendo reações metabólicas que favorecem a germinação (Carvalho \& Nakagawa, 2000). 
Métodos usados para superação da dormência em espécies exóticas e nativas têm servido para entender o comportamento fisiológico em diferentes ambientes. Estudos com esse foco atendem diferentes setores da sociedade em resposta à demanda de consumo, incluindo para recuperação de áreas degradadas e conservação de espécies nativas em situação vulnerável de extinção (Santos, et al., 2011).

Fatores são testados quanto à eficácia de procedimentos pré-germinação e dependem do tipo de dormência, a exemplo do estado de inibição (temporária ou longa) variável entre as espécies (Alves, et al., 2004; Barbosa, et al., 2005; Silva, et al., 2007). Atributos do substrato, como a fertilidade, também podem favorecer o desenvolvimento e a emergência do embrião, acelerando ou retardando o processo de germinação (Abreu, et al., 2017).

Em ambientes naturais, as espécies apresentam estratégias de germinação de suas sementes dependentes de intervenções naturais para superação de tegumentos intactos, através da escarificação ácida no trato digestivo de ruminantes e pássaros, escarificação enzimática de fungos e bactérias e embebição natural em solos umedecidos sob regime pluviométrico regular e luminosidade regular, para evitar proliferação de fungos (Souza, et al., 2013).

Estudos sobre o potencial das espécies vegetais e a viabilidade de suas sementes são relevantes e fornecem subsídios sobre propagação, que dependerá do ambiente em garantir propágulos sadios e viáveis para uso imediato (Souza, et al., 2013). Smirdele et al. (2005) e Rodrigues et al. (2008) sugerem métodos mecânico e químico por serem de baixo custo, fácil acesso, tempo reduzido e não demandarem técnicas especializadas. Apesar de informação abundante sobre dormência, a escassez de estudos sobre um substrato mais adequado para germinação e viabilidade dos propágulos impede ações e manejos em programas de recuperação de áreas antropizadas (Cardoso, 2004).

O método convencional para superação de dormência continua sendo base para a compreensão da atividade metabólica e os recursos fisiológicos que as sementes apresentam como estratégia de defesa contra herbivoria e invasão por organismos patogênicos. Um mecanismo natural de sobrevivência contra intempéries e essencial ao sucesso de colonização em função das características de cada espécie.

Este trabalho avaliou o potencial de germinação das sementes de duas espécies arbóreas, exótica e nativa, de Fabaceae, como estratégias para colonização de ambiente degradado. A família Fabaceae é caracterizada por uma acentuada dormência tegumentar (Rodrigues Filho, 2017).

A espécie exótica Leucaena leucocephala (Lam.) de Wit, conhecida como leucena, tem grande potencial para adaptarse em qualquer ambiente, sendo considerada invasora ou ruderal, dependendo do autor (Richardson, et al., 2000; Costa \& Durigan, 2010). Esta espécie de leguminosa perene apresenta crescimento rápido e associa-se com bactérias fixadoras de nitrogênio e fungos micorrízicos para assimilação do fósforo. Sua raiz profunda permite a exploração de camadas do subsolo e crescimento em substrato pobre e ácido característico de área degradada, onde tolera a seca e outras condições adversas (Kluthcouski, 1980).

A outra espécie é a nativa Enterolobium contortisiliquum (Vell.) Morong, de nome popular tamboril, é decídua e apresenta crescimento rápido, fazendo também associação com bactérias fixadoras de nitrogênio. Suas sementes têm dormência tegumentar. Esta espécie ocorre na Mata Atlântica, onde tem preferência por solos úmidos (Santos, et al., 2011). É considerada pioneira longeva/secundária inicial de floresta semidecídua (Dalling \& Brown, 2009).

\section{Metodologia}

\section{Escarificação física e química para superação da dormência}

A germinação de sementes de duas espécies, exótica e nativa, da família Fabaceae foi analisada comparativamente após a aplicação de dois tratamentos de escarificação, física e química, para superação da dormência. Os procedimentos adotados nesse estudo foram baseados nos métodos aplicados por Abreu et al. (2017). 
Sementes extraídas de frutos coletados em árvores de Leguminosae e Mimosoideae, plantadas no Arvoredo do Campus II da Universidade do Estado da Bahia em Alagoinhas (Bahia, Brasil), estavam armazenadas a seco em potes de vidro fechados com tampa, mas mantidas fora de refrigeração por cerca de 1 ano.

Apenas as sementes íntegras de leucena e tamboril foram submetidas à escarificação física (temperatura alta) e química (ácido concentrado). Foram selecionadas 60 sementes de cada espécie, das quais 20 foram submetidas à cocção a $100^{\circ} \mathrm{C}$ por 10 minutos, outras 20 foram imersas em ácido sulfúrico $\left(\mathrm{H}_{2} \mathrm{SO}_{4}\right)$ concentrado $95 \%$ por 15 minutos e mais 20 sementes como grupo controle (não tratadas).

Na escarificação física, as sementes foram escorridas após a cocção; enquanto, na escarificação química, as sementes foram lavadas em água corrente até a remoção completa do ácido sulfúrico. As sementes ficaram em repouso até a secagem por 1 dia e então embebidas em $250 \mathrm{ml}$ de água corrente por um período de 10 dias, com o recipiente mantido em sala escura para não sofrer interferência da luminosidade. As sementes do grupo controle não receberam tratamento.

Posteriormente, as sementes foram semeadas em dois substratos separados, terra vegetal e vermiculita, dentro de uma bandeja plástica $(36 \mathrm{~cm} \times 23 \mathrm{~cm} \times 3 \mathrm{~cm}$ ), regadas a cada 2 dias durante 10 dias. Foram monitorados dados de $\mathrm{pH}$ com fita $(\sim 7) \mathrm{e}$ de temperatura $\left(28 \pm 1^{\circ} \mathrm{C}\right)$ com termômetro digital de solos em ambos os substratos.

\section{Resultados e Discussão}

\section{Potencial de germinação das espécies como estratégia de colonização}

Neste trabalho, os tratamentos por escarificação física e química mostraram diferentes efeitos para superação da dormência e germinação das sementes entre as espécies exótica e nativa.

A escarificação física por cocção $\left(100^{\circ} \mathrm{C}\right.$ por $\left.10 \mathrm{~min}\right)$ inviabilizou os embriões nas sementes das duas espécies (Figura 1).

Após a escarificação ácida (15 min), o potencial de germinação da espécie nativa E. contortisiliquum (tamboril) foi o dobro da exótica L. leucocephala (leucena), após superação da dormência por escarificação ácida, nos dois substratos. Mesmo com baixa germinação, os valores foram de $15 \%$ e $20 \%$ para a exótica leucena e $30 \%$ a $40 \%$ para a nativa tamboril, respectivamente em terra vegetal e vermiculita (Figura 1).

Apenas sementes da espécie exótica $L$. leucocephala (leucena), de fácil superação da dormência, germinou no grupo controle nos dois substratos (Figura 1).

A emergência de plântulas da espécie exótica ocorreu a partir do terceiro dia após a escarificação química com ácido e no grupo controle não tratado. A espécie nativa E. contortisiliquum teve emergência de suas plântulas apenas nos quinto e sétimo dias somente no tratamento da escarificação química com ácido em ambos os substratos, mas a germinação foi irregular.

Comparando os resultados entre sementes escarificadas com ácido e o grupo controle, os substratos terra vegetal e vermiculita, com alta capacidade de retenção de água, não exerceram influência direta na germinação (Figura 1). 
Figura 1: Percentual de germinação de sementes das espécies exótica Leucaena leucocephala (leucena) e nativa Enterolobium contortisiliquum (tamboril), tratadas com diferentes métodos de escarificação física e química para superação da dormência.
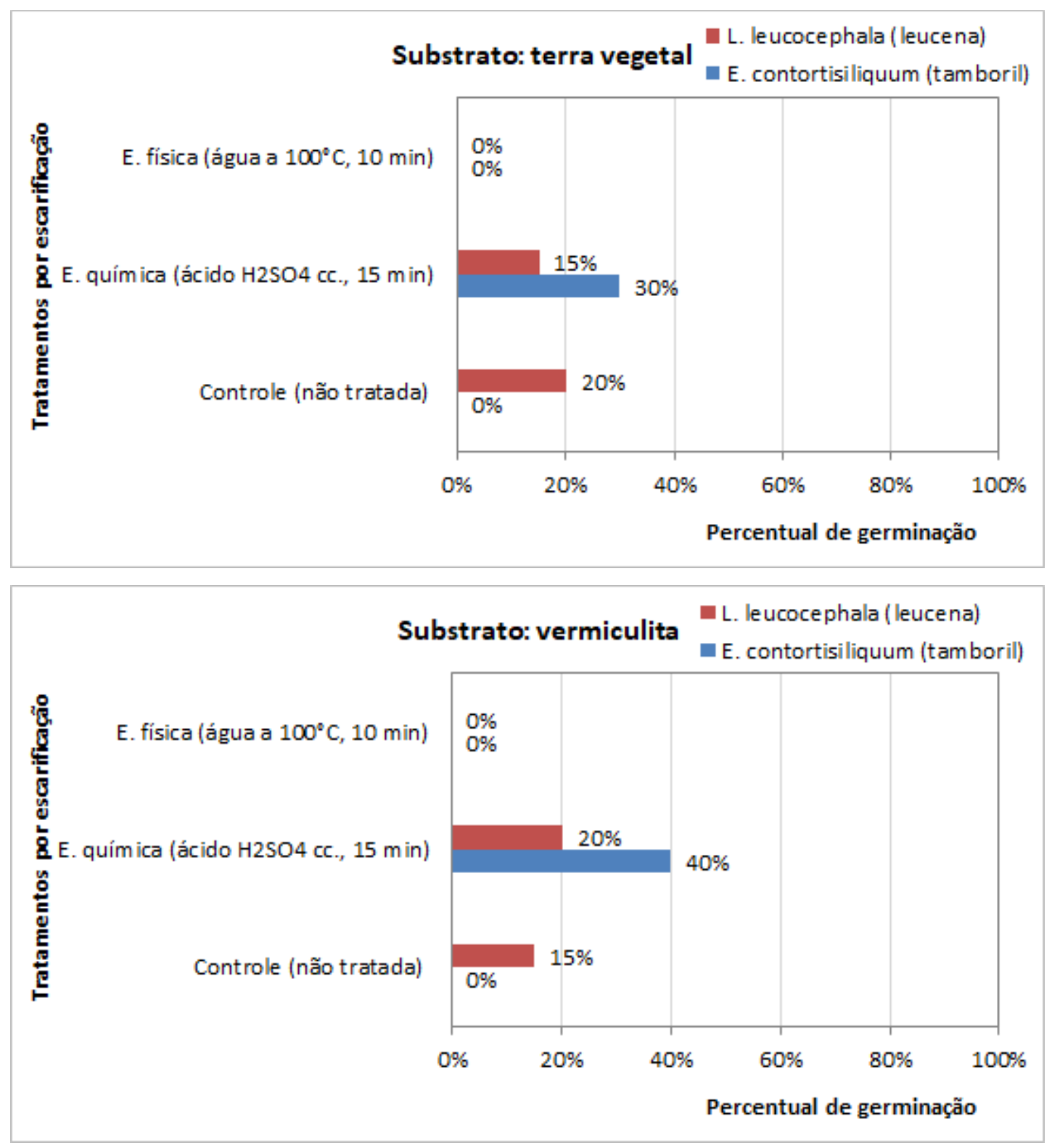

Fonte: Autores, a partir dos dados analisados (2020).

A dureza do tegumento é uma condição básica que impede a embebição e interfere na germinação da semente, mas outro fator limitante para a superação da dormência é a umidade. O tegumento rígido da semente torna-se progressivamente duro e impermeável à medida que o grau de umidade diminui (Bewley \& Black, 1982). Então a escarificação é necessária para romper a película que envolve a semente, aumentando a permeabilidade à água e estimulando a germinação, com consequente superação da dormência (Seiffert, 1982; Alexandre, et al., 2009).

Em relação à umidade, os substratos terra vegetal e vermiculita têm alta capacidade de retenção de água e isso pode explicar a germinação das sementes da espécie exótica (leucena) no grupo controle devido a sua baixa exigência fisiológica para superar a dormência. Entretanto, a terra vegetal, ao reter umidade, fica também mais suscetível à proliferação de microorganismos e agentes patogênicos, que podem atacar o embrião e degradar as substâncias de reservas da semente, impedindo sua germinação (Aguiar, 1990). A vermiculita é um mineral capaz de armazenar água e nutrientes do solo. Durante a estiagem, ela serve como fonte de nutrientes para liberação conforme aumenta a temperatura do solo, impedindo o ressecamento da terra, 
sendo indicada para áreas de reflorestamento e cultivos. Em terreno argiloso, ela aumenta a porosidade entre as frações granulométricas finas (Lima, 2010).

O uso de água quente, com uma temperatura que não mate o embrião, também é uma opção para amolecer o tegumento das sementes e contribuir para tornar essa barreira mais permeável (Perez, 2004). O tratamento com água quente é um método simples de executar, mas apresenta resultados inconsistentes, o que pode comprometer os mecanismos fisiológicos e até mesmo a viabilidade das sementes (Lêdo, 1977).

Kluthcouski (1980) indicou a imersão em água a $80^{\circ} \mathrm{C}$ por 3-4 minutos com semeadura imediata para superação da dormência de sementes da espécie exótica L. leucocephala (leucena). Smirdele et al. (2005) também obtiveram máxima emergência para outra espécie de leguminosa, igualmente exótica e invasora, a Acacia mangium, após escarificação com imersão em água a $100^{\circ} \mathrm{C}$ por apenas 1 minuto.

Em tratamento similar para a espécie nativa E. contortisiliquum (tamboril), Lêdo (1977) registrou perda de viabilidade das sementes imersas por 1-3 minutos. Donato et al. (2010) também usaram tratamento similar por 3 minutos, mas obtiveram 62,5\% de germinação em relação a 34,5\% após escarificação com ácido sulfúrico por 5 minutos. Santos et al. (2011) recomendam o choque térmico com água a $98^{\circ} \mathrm{C}$ por 3-4 minutos seguida de água fria por mais 5 minutos, obtendo $62,5 \%$ de germinação sobre $46,25 \%$ após escarificação por ácido.

O ácido sulfúrico concentrado mostrou ser eficiente em testes de escarificação de sementes de leguminosas (Seiffert, 1982). Alcaly e Amaral (1982) e Aquino et al. (2009) demonstraram que tratamentos pré-germinativos com o ácido são os mais indicados para superação de dormência da espécie nativa E. contortisiliquum (tamboril). Lêdo (1977) alcançou germinação da semente com escarificação pelo ácido após 1 hora e 30 minutos, mas recomendou a escarificação mecânica por 9 segundos pela eficiência e aplicação prática do tratamento sem risco à saúde.

Apesar dos resultados satisfatórios com escarificação ácida registrados na literatura, a germinação das espécies exótica e nativa foi considerada baixa neste estudo e pode ser explicada por: i) longo período de armazenamento das sementes com comprometimento de sua viabilidade e ii) luminosidade deficiente do local de manutenção da bandeja com consequente proliferação de fungos, o que pode ter inviabilizado os embriões na maior parte das sementes. A espécie é nativa de floresta tropical e, portanto, está adaptada a alta luminosidade.

A escarificação ácida com sementes do mesmo lote, mas usadas logo após coleta das árvores, deu melhor resultado ao ponto de Dantas e Matos (2014) indicarem o tratamento ácido como método mais eficaz para superação da dormência.

O uso da espécie nativa E. contortisiliquum como pioneira é uma alternativa viável e ecologicamente adequada em substituição da exótica empregada para colonização de área degradada. Em condições naturais, a superação da dormência e a germinação de sementes podem ocorrer após tratamento ácido no estômago dos dispersores, como aves e mamíferos terrestres, e a umidade do solo não é fator limitante. Zama et al. (2012) indicam esta espécie nativa como pioneira em solos úmidos e frequente em floresta secundária, com síndrome de dispersão zoocórica. O fato de ser uma espécie nativa faz dela uma legítima substituta de espécies exóticas, no papel ecológico de pioneira ou secundária inicial, para recuperação de áreas degradadas no bioma Mata Atlântica.

A baixa exigência fisiológica da espécie exótica $L$. leucocephala (leucena) foi observada no grupo controle pela rápida superação da dormência e germinação. Porém sementes não tratadas da espécie nativa não germinaram. Dado similar também foi registrado por Alexandre et al. (2009). O baixo nível de germinação da semente da espécie nativa E. contortisiliquum (tamboril) pode ser atribuído à espessura do seu tegumento (Alexandre, et al., 2009; EMBRAPA, 2010).

Em outro tratamento de escarificação mecânica, Kluthcouski (1980) e Teles et al. (2000) obtiveram, respectivamente, menos de $50 \%$ e 32,7\% de germinação das sementes não-tratadas da espécie exótica L. leucocephala (leucena). Kluthcouski (1980) indicou areia em agitador mecânico ou uso de lixa para superação da dormência. Alexandre et al. (2009), Rodrigues Filho 
(2017) e Silva et al. (2020) também apresentaram a escarificação mecânica como método alternativo eficiente para quebra de dormência da espécie arbórea nativa E. contortisiliquum (tamboril). Ela parece requerer uma combinação com outras variáveis ambientais características naturais de Floresta Atlântica de procedência da espécie (Santana, et al., 2008).

A rápida germinação na espécie exótica leucena $L$. leucocephala permite inferir sobre sua maior eficiência na estratégia de colonização e capacidade de invadir áreas degradadas, sob efeito de borda em remanescentes de Mata Atlântica, cada vez mais fragmentados. A leucena é considerada uma espécie invasora e também ruderal em áreas degradadas e está relacionada à perda de biodiversidade (Costa \& Durigan, 2010). Para ser considerada invasora, uma espécie deve reproduzir-se em ecossistemas naturais, sem intervenção humana, ao ponto de reduzir a abundância ou substituir espécies nativas (Richardson, et al., 2000).

As espécies da família Fabaceae apresentam sementes de dormência tegumentar, germinação variando de lenta a rápida e irregular (Rodrigues Filho, 2017). A rápida germinação da espécie exótica L. leucocephala (leucena) pode torná-la uma invasora eficiente e agressiva em ambientes antropizados.

A baixa exigência fisiológica para superação da dormência e a rápida germinação das sementes da espécie exótica compõem uma estratégia de colonização ambiental que permite suplantar as espécies concorrentes. Apesar desta espécie exótica ser considerada ruderal por Costa e Durigan (2010), o fato dela proliferar e dificultar a instalação de espécies nativas conferelhe um caráter indesejado para recuperação de área degradada sob efeito de borda, por exemplo, podendo formar manchas monoespecíficas. Muitas espécies exóticas de diferentes famílias botânicas vêm sendo usadas na arborização inadequada de praças, parques e jardins públicos de cidades brasileiras, sem valorização da flora nativa com características adequadas para este mesmo fim (Santos, et al., 2021).

Por outro lado, as espécies nativas parecem usar o mecanismo de dormência, pela impermeabilidade do tegumento, como estratégia para um processo lento e irregular de germinação, de maneira a distribuir a propagação da própria espécie por mais tempo ao longo do ciclo fenológico. O mesmo argumento foi apresentado por Alexandre et al. (2009). Este auto-controle da população permite que outras espécies próximas e viáveis possam também desenvolver-se. Isto conforma a biodiversidade que contribui para manter mecanismos de controle biológico, regulação dos processos ecológicos e equilíbrio a caminho do estádio clímax.

Portanto, nesta abordagem ecológica, a germinação da espécie nativa E. contortisiliquum (tamboril) superior à da espécie exótica L. leucocephala, após a escarificação para superação da dormência, justifica seu uso como pioneira longeva/secundária inicial de floresta semidecídua para atração de dispersores na recuperação de áreas degradadas (Araújo \& Sobrinho, 2011). Com o aumento da fragmentação de remanescentes em florestas tropicais, o manejo correto deve contemplar espécies arbóreas nativas, entre as várias opções da mesma família Fabaceae e de outras tantas em planos de recuperação de áreas degradadas, com valorização da flora nativa exuberante adequada e adaptada ao clima tropical (Santos, et al., 2021). Portanto, considerando o potencial de germinação, a espécie arbórea nativa E. contortisiliquum tem seu plantio propagado de forma moderada e sem afetar outras espécies vegetais nativas, podendo ser uma alternativa viável para recuperação de áreas degradadas na mesma Mata Atlântica e em outros ecossistemas tropicais brasileiros, onde possui ampla distribuição.

\section{Considerações Finais}

A baixa porcentagem de germinação das sementes de leucena e tamboril pode estar relacionada à perda de viabilidade pelo armazenamento prolongado.

A escarificação física por cocção inviabilizou os embriões das sementes das duas espécies, houve germinação da espécie exótica do grupo controle nos dois substratos. 
A escarificação química por ácido foi eficiente nas sementes das duas espécies. Apesar de baixo, o potencial de germinação da espécie nativa, $30 \%$ e $40 \%$, foi o dobro da espécie exótica, $15 \%$ e $20 \%$, respectivamente em terra vegetal e vermiculita.

O ácido sulfúrico concentrado mostrou ser o melhor tratamento usado para superação da dormência e germinação das sementes sem interferir em seu vigor. Por ser inviável para uso cotidiano, pode ser substituído pela escarificação mecânica para ambas as espécies.

O resultado do grupo controle mostrou que o tipo de substrato não influenciou o processo de germinação.

Espécies exóticas são invasoras agressivas pela baixa exigência para germinação e consequente eficiência de colonização de áreas antropizadas.

Em condições naturais, a superação da dormência e a germinação de sementes podem ocorrer após tratamento ácido no estômago dos dispersores, como aves e mamíferos terrestres, e umidade do solo.

O potencial de germinação da espécie nativa E. contortisiliquum, superior ao da exótica L. leucocephala, configura uma vantagem estratégica da espécie nativa e valoriza seu papel ecológico como pioneira longeva/secundária inicial de floresta semidecídua na recuperação de áreas degradadas do domínio Mata Atlântica no estado da Bahia (Brasil).

\section{Referências}

Abreu, D. C. A., Porto, K. G., \& Nogueira, A. C. (2017). Métodos de superação da dormência e substratos para germinação de sementes de Tachigali vulgaris L.G. Silva \& H. C. Lima. Floresta e Ambiente, 24, 2-10.

Aguiar, F. F. A. (1990). Efeito de diferentes substratos e condições ambientais na germinação de sementes de Euterpe edulis Mart. e Geonoma schottiana Mart. Acta Bot. Bras, 4 (2), 1-7. 10.1590/S0102-33061990000300001

Alcalay, N., \& Amaral, D. M. I. (1982). Quebra de dormência em sementes de timbaúva - Enterolobium contortisiliquum (Vell.) Morong. Silvicultura em São Paulo, 16, 1149-1152.

Alexandre, R. S., Gonçalves, F. G., Rocha, A. P., Arruda, M. P., \& Lemes, E. Q. (2009). Tratamentos físicos e químicos na superação de dormência em sementes de Enterolobium contortisiliquum (Vell.) Morong. Recife, PE. Rev. Bras. Ciênc. Agrár, 4 (2), 156-159.

Alves, A. U., Dornelas, C. S. M., Bruno, R. L. A., Andrade, L. A., \& Alves, E. U. (2004). Superação da dormência em sementes de Bauhinia divaricata L. Acta Botânica Brasílica, 18 (4), 871-879.

Aquino, A. F. M. A. G., Ribeiro, M. C. C., Paula, Y. C. M., \& Benedito, C. P. (2009). Superação de dormência em sementes de orelha de negro (Enterolobium contortisiliquum (Vell.) Morong.). Revista Verde, 4 (1), 69-75.

Araújo, A. P., \& Sobrinho, S. P. (2011). Germinação e produção de mudas de tamboril (Enterolobium contortisiliquum (Vell.) Morong) em diferentes substratos. Revista Árvore, 35 (3), 581-588.

Barbosa, J. G., Alvarenga, E. M., Dias, D. C. F. S., \& Vieira, A. N. (2005). Efeito da escarificação ácida e de diferentes temperaturas na qualidade fisiológica de sementes de Strelitzia reginae. Revista Brasileira de Sementes, 27 (1), 71-77.

Bewley, J., \& Black, M. (1982). Physiology and biochemistry of seeds in relation to germination: viability, dormancy and environmental control. Berlin: Springer-Verlag, 2, 375 .

Cardoso, V. J. M. (2004). Dormência: estabelecimento do processo. In Ferreira, A. G.; Borguetti, F. (Orgs). Germinação: do básico ao aplicado. Porto Alegre: Artmed, 95-134.

Cardoso, V. J. M. (2009). Conceito e classificação da dormência em sementes. Oecologia Brasiliensis, 13, (4), 619-630.

Carvalho, N. M., \& Nakagawa, J. (2000). Sementes: ciência, tecnologia e produção. (4a ed.), FUNEP, 588.

Costa, J. N. M. N. da., \& Durigan, G. (2010). Leucaena leucocephala (Lam.) de Wit (Fabaceae): invasora ou ruderal? Revista Árvore, 34, (5), 825-833, 2010. https://www.scielo.br/pdf/rarv/v34n5/08.pdf.

Coutinho, R.Q., Lima, M.F., Neto, J.B.S., \& Silva, E.P. (1998). Características climáticas, geológicas, geomorfológicas e geotécnicas da Reserva Ecológica de Dois Irmãos. In Reserva Ecológica de Dois Irmãos: Estudos em um remanescente de Mata Atlântica em área urbana. I.C. Machado, A.V., \& Lopes, K.C. Porto (Eds.). Secretaria de Ciência, Tecnologia e Meio Ambiente/Editora Universitária-Universidade Federal de Pernambuco, Recife, 21-50.

Dalling, J. W., \& Brown, T. A. (2009). Long-Term Persistence of Pioneer Species in Tropical Rain Forest Soil Seed Banks. The American Naturalist, 173 (4), 5 . 
Dantas, J. A. S. \& Matos, M. R. B. (2014). Educação Ambiental em comunidades ribeirinhas: restauração de Mata Ciliar e ações sustentáveis nas microbacias do rio Catu e Quiricó. Jornada de Iniciação Científica da UNEB. Anais da XVIII Jornada de Iniciação Científica da UNEB, Salvador: EDUNEB, 218-219. https://portal.uneb.br/ppg/jornadas-de-inicialcao-cientifica/.

Donato, D. B., Fonseca, A. G., Assis Júnior, S. L., Machado, E. L. M., \& Bispo, D. F. A. (2010). Dano de Caryedes sp. (Coleoptera; Bruchidae) e seus reflexos na propagação de Enterolobium contortisiliquum (Leguminosae). Floresta e Ambiente, 17, (2), 118-123.

EMBRAPA, Semiárido. (2010). Sistemas de Produção, 6 Versão Eletrônica. http://sistemasdeproducao.cnptia.embrapa.br/FontesHTML/Melan cia/SistemaProducaoMelancia/plantio.htm.

Lima JR., M. J. (2010). (Ed.) Manual de procedimentos para análise de sementes florestais. UFAM - CSNAM, 146.

Kluthcouski, J. (1982). Leucena: alternativa para a pequena e média agricultura. Brasília: EMBRAPA, (2a. ed.) Brasília, DF. Circular Técnica, (6), 1-12. https://www.embrapa.br/busca-de-publicacoes/-/publicacao/192292/leucena-alternativa-para-a-pequena-e-media-agricultura

Lêdo, A. A. M. (1977). EstudMBRAPAo da causa da dormência em sementes de guapuruvu (Schizolobium parahybum (Vell.) Blake) e orelha de negro (Enterolobium contortisiliquum (Vell. Morong) e métodos para sua quebra. Dissertação de mestrado, Universidade Federal de Viçosa, Viçosa, MG, 57.

Marcos Filho, J. (2005). Fisiologia de sementes de plantas cultivadas. FEALQ, 495.

Metivier, J. R. (1979). Dormência e germinação. In Ferri, Mário Guimarães (Coord.). Fisiologia Vegetal 2. EPU \& EDUSP, $343-392$.

Perez, S. C. J. G. A. Envoltórios. In Ferreira, A. G., \& Borghetti, F. (2004). (Orgs). Germinação: do básico ao aplicado. Artmed, $125-134$.

Richardson, D. M., Pysek, P., Rejmánek, M., Barbour, M. G., Panetta, F. D., \& West, C. J. (2000). Naturalization and invasion of alien plants: concepts and definitions. Diversity and Distributions, (6), 93-107.

Rodrigues, A. P. A. C., Kohl, M. C., Pedrinho, D. R., Arias, E. R. A., \& Favero, S. (2008). Tratamentos para superar a dormência de sementes de Acacia mangium Willd. Acta Scientiarum: Agronomy, 30 (2), 279-283.

Rodrigues Filho, J. (2017). Dormência em espécies arbóreas de dois biomas brasileiros. Dissertação (Mestrado em Biologia Vegetal), UFES. Vitória, ES, 85.

Santana, G. C., Mann, R. S., Ferreira, R. A., Gois, I. B., Oliveira, A. S., Boaki, A. J., \& Carvalho, S. V. A. (2008). Diversidade genética de Enterolobium contortisiliquum (Vell.) Morong. no baixo rio São Francisco, por meio de marcadores RAPD. Rev. Árvore, 32 (3), 427-433. 10.1590/S0100-67622008000300005

Santos, A. L. F., Freire, J. M., \& Piña-Rodrigues, F. C. M. (2011). Avaliação de métodos para superação de dormência de sementes de leguminosas arbóreas utilizadas na recuperação de áreas degradadas. Seropédica, RJ. EMBRAPA Agrobiologia, Boletim de Pesquisa e Desenvolvimento, (76), 1-36. https://ainfo.cnptia.embrapa.br/digital/bitstream/item/76438/1/bot076-112013.pdf

Seiffert, N. F. (1982). Métodos de escarificação de sementes de leguminosas forrageiras tropicais. Campo Grande, MS: EMBRAPA Gado de Corte. Comunicado Técnico, (13), 1-6. https://ainfo.cnptia.embrapa.br/digital/bitstream/item/138495/1/COT-13.pdf

Silva, K. B., Alves, E. U., Bruno, R. L. A., Gonçalves, E. P., Braz, M. S. S., \& Viana, J. S. (2007). Quebra de dormência em sementes de Erythrina velutina Willd. Revista Brasileira de Biociências, 5 (2), 180 -182.

Silva, M. F., Silva, J. N., Alves, R. M., Silva, E. F., \& Silva, M. A. D. (2020) Métodos alternativos ao ácido sulfúrico para superação de dormência das sementes de Enterolobium contortisiliquum (tamboril). Research, Society and Development, 9, (8), 10.

Silva, W. S., Orge, M. D. R., Dantas, J. A. S., Matos, M. R. B., \& Luz, L. S. (2021) Espécies nativas da Mata Atlântica para restauração ambiental, conservação da biodiversidade e desenvolvimento urbano sustentável (Bahia, Brasil). In Kristian Andrade Paz de la Torre. (Org.). Desenvolvimento Sustentável, Interdisciplinaridade e Ciências Ambientais 2. 1a. ed. Ponta Grossa: Atena Editora, (1), pp. 160-176.

Smirdele, O. J., Mourão Júnior, M., \& Sousa, R. C. P. (2005). Tratamentos pré-germinativos em sementes de acácia. Revista Brasileira de Sementes, 27, (1), 78-85. 10.1590/S0101-31222005000100010

Souza P. S., Rigo, M. M., Cerqueira, A. A., Ferreira, A. C., Marques, M. R., \& Perez, D. V. (2013). Efeito de diferentes dosagens de Fe3+ na germinação do girassol. Revista Internacional de Ciências, 3, (2), 73-82.

Teles, M. M., Alves, A. A., Oliveira, J. C. G., \& Bezerra, A. M. E. (2000). Métodos para a quebra da dormência em sementes de leucena (Leucaena leucocephala (Lam.) de Wit). Viçosa, MG. Revista Brasileira de Zootecnia, 29 (2), 387-391.

Zana, M. Y., Bovolenta, Y. R., Carvalho, E. S., Rodrigues, D. R., Araujo, C. G., Sorace, M. A. F., \& Luz, D. G. (2012). Florística e síndromes de dispersão de espécies arbustivo-arbóreas no Parque Estadual Mata São Francisco, PR, Brasil. Hoehnea, 39, (3), 369-378. 